\title{
Filippi syndrome
}

INSERM

\section{Source}

INSERM. (1999). Orphanet: an online rare disease and orphan drug data base. Filippi syndrome. ORPHA:3255

Filippi syndrome is characterised by microcephaly, cutaneous syndactyly of the fingers and toes, intellectual deficit, growth retardation and a characteristic facies (high and broad nasal bridge, thin alae nasi, micrognathia and a high frontal hairline). So far, less than 25 cases have been reported. Cryptorchidism, polydactyly, and teeth and hair anomalies may also be present. Transmission is autosomal recessive. 